\title{
Sea level change in Great Britain between 1859 and the present
}

\author{
Philip L. Woodworth \\ National Oceanography Centre, Joseph Proudman Building, 6 Brownlow Street, Liverpool L3 5DA, UK. E-mail: plw@noc.ac.uk
}

Accepted 2017 December 15. Received 2017 December 5; in original form 2017 September 18

\begin{abstract}
SUMMAR Y
Short records of sea level measurements by the Ordnance Survey at 31 locations in 1859-1860, together with recent Mean Sea Level (MSL) information from the UK tide gauge network, have been used to estimate the average rates of sea level change around the coast of Great Britain since the mid-19th century. Rates are found to be approximately $1 \mathrm{~mm} \mathrm{yr}^{-1}$ in excess of those expected for the present day based on geological information, providing evidence for a climate-change related component of the increase in UK sea level. In turn, the rates of change of MSL for the past $60 \mathrm{yr}$ are estimated to be $\sim 1 \mathrm{~mm} \mathrm{yr}^{-1}$ in excess of the long-term rates since 1859, suggesting an acceleration in the rate of sea level rise between the 19th and $20 \mathrm{th} / 21$ st centuries. Although the historical records are very short (approximately a fortnight), this exercise in 'data archaeology' shows how valuable to research even the shortest records can be, as long as the measurements were made by competent people and the datums of the measurements were fully documented.
\end{abstract}

Key words: Geodetic instrumentation; Global change from geodesy; Sea level change.

\section{INTRODUCTION}

The evidence for changes in sea level around the UK coast during the past two centuries is based on a small number of records from tide gauges (Woodworth 1999; Woodworth et al. 1999), supplemented by an even smaller number of salt marsh records (e.g. Long et al. 2014). Long-term rates of change in level are of the order of $\sim 1 \mathrm{~mm} \mathrm{yr}^{-1}$ for most of the coast, with lower rates on uplifting sections of the northern Scottish coastline (Barlow et al. 2014). A small acceleration with a quadratic coefficient of order $1 \mathrm{~mm}$ $\mathrm{yr}^{-1}$ per century is apparent in the three longest tide gauge records (Aberdeen, Sheerness and Liverpool), indicating larger rates of sea level rise during the 20th century than previously (Woodworth et al. 2009).

While the evidence for a long-term change in UK sea level may be convincing to most sea level specialists, it can only benefit from being confirmed using as many sources of information as possible. The source investigated here concerns the use of short historical records of sea level at sites near to where recent measurements have also been made, and where the historical and recent measurements have been made with respect to the same land datum (or to historic and recent datums that are relatable geodetically).

This approach to deriving long-term sea level trends is not as ideal as the conventional approach of using long, continuous tide gauge records. Nevertheless, it has been shown to provide useful information on trends when a large period of time has passed between the historical and recent sets of measurements. In particular, the method has been used in remote locations in the southern hemisphere where there are very few long, continuous records (e.g. Hunter et al. 2003; Testut et al. 2006, 2010; Watson et al. 2010;
Woodworth et al. 2010). However, although the value of using short historical records in studies of long-term sea level change in the UK has been recognized (e.g. Woodworth \& Jarvis 1991), the short records have never been employed in this way to any great extent so far.

There are potentially many sets of short historical records from the 19th century that could be used, from measurements by harbour authorities and national agencies such as the UK Hydrographic Office and Ordnance Survey (OS). They need to be catalogued, filtered (for suitability and priority) and digitized to make them available for research. Such work is one component of the 'data archaeology' of sea level information worldwide (Bradshaw et al. 2015) which should eventually lead to longer and more complete records (e.g. Hogarth 2014). Similar data rescue activities are in progress for other oceanographic and meteorological information (Allan et al. 2011; Levitus 2012).

In the present paper, we make use of one of the most suitable short data sets, which consists of sea level records from 31 sites around Great Britain obtained by the OS during 1859-1860 as part of the First Geodetic Levelling (FGL) of England and Wales (James 1861a,b). Table 1(a) provides a list and Fig. 1(a) shows in red the locations of the measurements. The records are very short (typically a fortnight) and were obtained during daylight hours only, mostly during summer 1859 in England and Wales and autumn 1859 in Scotland (Fig. 1b). Although they are short, it will be seen that they can provide estimates of historical sea level that can be combined with more recent data to provide useful information on sea level trends. An important aspect of this data set is that it was obtained by the Ordnance Survey, a geodetic agency which was completely reliable as far as the sea level measurements themselves were 
Table 1. (a) The 31 Ordnance Survey stations with measurements over a fortnight in 1859-1860. (b) Corresponding information for the additional stations discussed in Section 5.1. (c) Corresponding information from the $4 \mathrm{yr}$ of Liverpool MTL data (1854-1857) discussed in Section 5.1.

\begin{tabular}{|c|c|c|c|c|c|c|c|c|c|c|c|c|c|c|}
\hline (1) & (2) & (3) & (4) & (5) & (6) & (7) & (8) & (9) & (10) & (11) & (12) & (13) & (14) & (15) \\
\hline \multicolumn{15}{|l|}{ (a) } \\
\hline 1 & Appledore & 1859.500 & 0.690 & -0.600 & 2.743 & -3.292 & -1.700 & -6.873 & 14.607 & Ilfracombe & 1214 & 19 & 2000.011 & 18.026 \\
\hline 2 & Berwick & 1859.625 & 0.389 & -0.200 & 5.761 & -0.246 & -1.413 & -1.329 & 8.749 & North Shields & 95 & 47 & 1985.554 & 33.106 \\
\hline 3 & Birkenhead & 1859.833 & 1.113 & 0.100 & 36.972 & 8.010 & 4.039 & 4.315 & 20.609 & $\begin{array}{l}\text { L'pool } \\
\text { Gladstone }\end{array}$ & 1774 & 14 & 1999.387 & 30.771 \\
\hline $4^{*}$ & Cardigan & 1859.292 & 0.779 & 0.200 & 29.840 & -5.456 & -2.387 & 2.516 & 35.167 & Fishguard II & 1731 & 20 & 1999.858 & 17.260 \\
\hline 5 & Dover & 1859.583 & 0.417 & -1.400 & -29.962 & -0.060 & 2.052 & -1.632 & -30.322 & Dover & 255 & 43 & 1985.516 & 5.137 \\
\hline 6 & Falmouth & 1859.500 & -0.001 & -0.400 & -12.222 & -3.764 & 0.455 & -7.884 & -1.030 & Newlyn & 202 & 58 & 1983.631 & 12.469 \\
\hline 7 & Grimsby & 1859.583 & 1.814 & -1.600 & 6.523 & -0.617 & 0.507 & -0.614 & 7.247 & Immingham & 286 & 48 & 1985.271 & 16.060 \\
\hline 8 & Harwich & 1859.583 & 1.883 & -1.900 & -0.518 & 0.923 & 3.435 & -0.613 & -4.263 & Felixstowe & 214 & 20 & 1995.008 & 12.320 \\
\hline 9 & Holyhead & 1860.000 & 0.462 & 0.700 & 35.418 & 5.447 & 5.084 & 7.337 & 17.550 & Holyhead & 5 & 37 & 1985.526 & 19.289 \\
\hline 10 & Lowestoft & 1859.583 & 1.382 & -1.600 & -6.645 & 0.767 & 2.296 & -0.640 & -9.068 & Lowestoft & 754 & 54 & 1986.421 & 10.513 \\
\hline 15 & Silloth & 1860.083 & -0.663 & 0.400 & -8.016 & 3.837 & 2.305 & -9.444 & -4.714 & Workington & 1794 & 21 & 2002.625 & 35.524 \\
\hline 16 & S'ton & 1859.583 & 0.791 & -0.700 & 2.774 & -1.047 & 2.873 & -3.195 & 4.141 & Portsmouth & 350 & 44 & 1987.163 & 12.677 \\
\hline 17 & Torquay & 1859.500 & 0.433 & -0.600 & -5.090 & -4.918 & 3.458 & -8.555 & 4.924 & Plymouth & 982 & 43 & 1985.609 & 15.288 \\
\hline 18 & Weymouth & 1859.500 & 0.561 & -1.100 & -16.429 & -3.219 & 0.475 & -8.891 & -4.794 & Weymouth & 1773 & 19 & 2001.274 & 11.995 \\
\hline 19 & Weston-SM & 1859.417 & 0.121 & -0.700 & -17.648 & -6.141 & -2.479 & 5.861 & -14.888 & Hinkley Point & 1758 & 19 & 2000.853 & 33.089 \\
\hline 20 & Aberdeen & 1859.667 & 1.135 & -0.400 & 22.403 & 1.009 & -3.604 & 4.095 & 20.903 & Aberdeen & 361 & 50 & 1983.938 & 28.212 \\
\hline 21 & Ardrossan & 1859.708 & 0.310 & 0.800 & 33.833 & 1.017 & 1.444 & 10.534 & 20.838 & Millport & 755 & 30 & 1992.658 & 37.033 \\
\hline 22 & Ayr & 1859.667 & 0.329 & 0.900 & 37.460 & -0.408 & -2.930 & 0.448 & 40.350 & Millport & 755 & 30 & 1992.658 & 37.033 \\
\hline 22 & Ayr & 1859.667 & 0.329 & 0.900 & 37.460 & -0.410 & -2.930 & 0.912 & 39.887 & Portpatrick & 1215 & 40 & 1988.683 & 34.600 \\
\hline 23 & Banff & 1859.708 & 1.021 & -0.500 & 15.880 & 2.863 & -0.093 & 2.569 & 10.541 & Aberdeen & 361 & 50 & 1983.938 & 28.212 \\
\hline 24 & Dundee & 1859.667 & 0.999 & 0.000 & 30.450 & 1.508 & -2.377 & 2.894 & 28.424 & Leith II & 1526 & 21 & 2002.101 & 28.667 \\
\hline 24 & Dundee & 1859.667 & 0.999 & 0.000 & 30.450 & 1.693 & -2.377 & 2.900 & 28.233 & Leith & 802 & 13 & 1963.266 & 27.992 \\
\hline 25 & Granton Pier & 1859.667 & 0.398 & 0.300 & 21.275 & 1.508 & -6.430 & 0.725 & 25.472 & Leith II & 1526 & 21 & 2002.101 & 28.667 \\
\hline $31^{*}$ & Rispond & 1859.833 & 1.804 & -0.700 & 33.650 & 10.212 & 4.479 & -4.143 & 23.102 & Kinlochbervie & 1775 & 16 & 2002.896 & 37.738 \\
\hline \multicolumn{15}{|l|}{ (b) } \\
\hline 41 & Fleetwood & 1841.875 & 0.661 & 0.100 & 23.195 & 9.062 & 14.900 & 0.000 & -0.767 & Heysham & 936 & 32 & 1984.083 & 24.763 \\
\hline 42 & Hull & 1851.625 & 0.688 & -0.600 & 2.682 & 1.039 & -2.000 & 0.000 & 3.643 & Immingham & 286 & 48 & 1985.271 & 16.060 \\
\hline 43 & Lyme Cobb & 1849.917 & 1.490 & -0.800 & 21.031 & 5.166 & 2.000 & 0.000 & 13.866 & Weymouth & 1773 & 19 & 2001.274 & 11.995 \\
\hline 44 & Pembroke & 1837.000 & 0.554 & 0.100 & 19.934 & 0.000 & 5.500 & 0.000 & 14.434 & $\begin{array}{l}\text { Milford Haven } \\
\text { (Hakin) }\end{array}$ & 1700 & 18 & 1999.792 & 14.578 \\
\hline 45 & Plymouth & 1837.000 & -0.359 & -0.500 & -26.182 & 0.000 & -16.200 & 0 & 82 & Plymouth & 982 & 43 & 609 & 15.288 \\
\hline 46 & Portsmouth & 1837.000 & & -0.700 & -12.1 & & -8.2 & & -3 & & 350 & 44 & & 12.677 \\
\hline 47 & N Shields & 1855.500 & 0.990 & 0.200 & 36.271 & 0.000 & 0.300 & 0.000 & 35.971 & North Shields & 95 & 47 & 1985.554 & 33.106 \\
\hline 48 & Sunderland & 1847.500 & 0.714 & 0.200 & 27.859 & 0.000 & 0.300 & 0.000 & 27.559 & North Shields & 95 & 47 & 1985.554 & 33.106 \\
\hline 61 & Ardrissaig & 1850.858 & 1.107 & -1.100 & 0.213 & 0.225 & -5.400 & 0.000 & 5.388 & Port Ellen & 1772 & 19 & 2000.958 & 27.732 \\
\hline 62 & Campbelton & 1857.750 & 0.394 & 1.100 & 45.537 & 4.899 & -5.400 & 0.000 & 46.038 & Millport & 755 & 30 & 1992.658 & 37.033 \\
\hline 63 & Crinan & 1850.000 & 0.258 & 2.400 & 81.016 & -2.430 & 2.100 & 0.000 & 81.345 & Port Ellen & 1772 & 19 & 2000.958 & 27.732 \\
\hline 64 & Thurso & 1843.500 & 1.160 & -0.800 & 10.973 & -0.871 & 2.700 & 0.000 & 9.144 & Wick & 1109 & 42 & 1989.149 & 33.631 \\
\hline 65 & Wick & 1850.000 & 0.290 & -0.800 & -15.545 & 0.000 & 2.700 & 0.000 & -18.245 & Wick & 1109 & 42 & 1989.149 & 33.631 \\
\hline \multicolumn{15}{|l|}{ (c) } \\
\hline 71 & Liverpool & 1856.000 & 0.298 & 0.100 & 12.131 & 0.000 & 6.500 & 0.000 & 5.631 & $\begin{array}{l}\text { L'pool } \\
\text { Gladstone }\end{array}$ & 1774 & 14 & 1999.387 & 30.771 \\
\hline
\end{tabular}

Columns show: (1) Station number of the historical measurements, (2) station name, and (3) the central time of the fortnight of measurements, followed by (4) average sea level for the historical period (in $\mathrm{ft}$ to ODL datum), (5) the conversion from ODL to ODN datum (ft), and (6) the resulting sea level in $\mathrm{cm}$ with respect to ODN datum. There follows (7-9) the seasonal, tidal and air pressure corrections (cm), and (10) the best estimate of annual MSL at that time in the 19th century after applying those corrections (cm to ODN). The right-hand side gives (11) the name of the nearest station with recent PSMSL data, (12) its code number, (13) number of years of data within 1955-2014, (14) the central time of the MSL data, and (15) the average MSL for 1955-2014 relative to ODN (cm). Entries with an asterisk after the station number in column 1 refer to rejected station pairs as discussed in the text. 

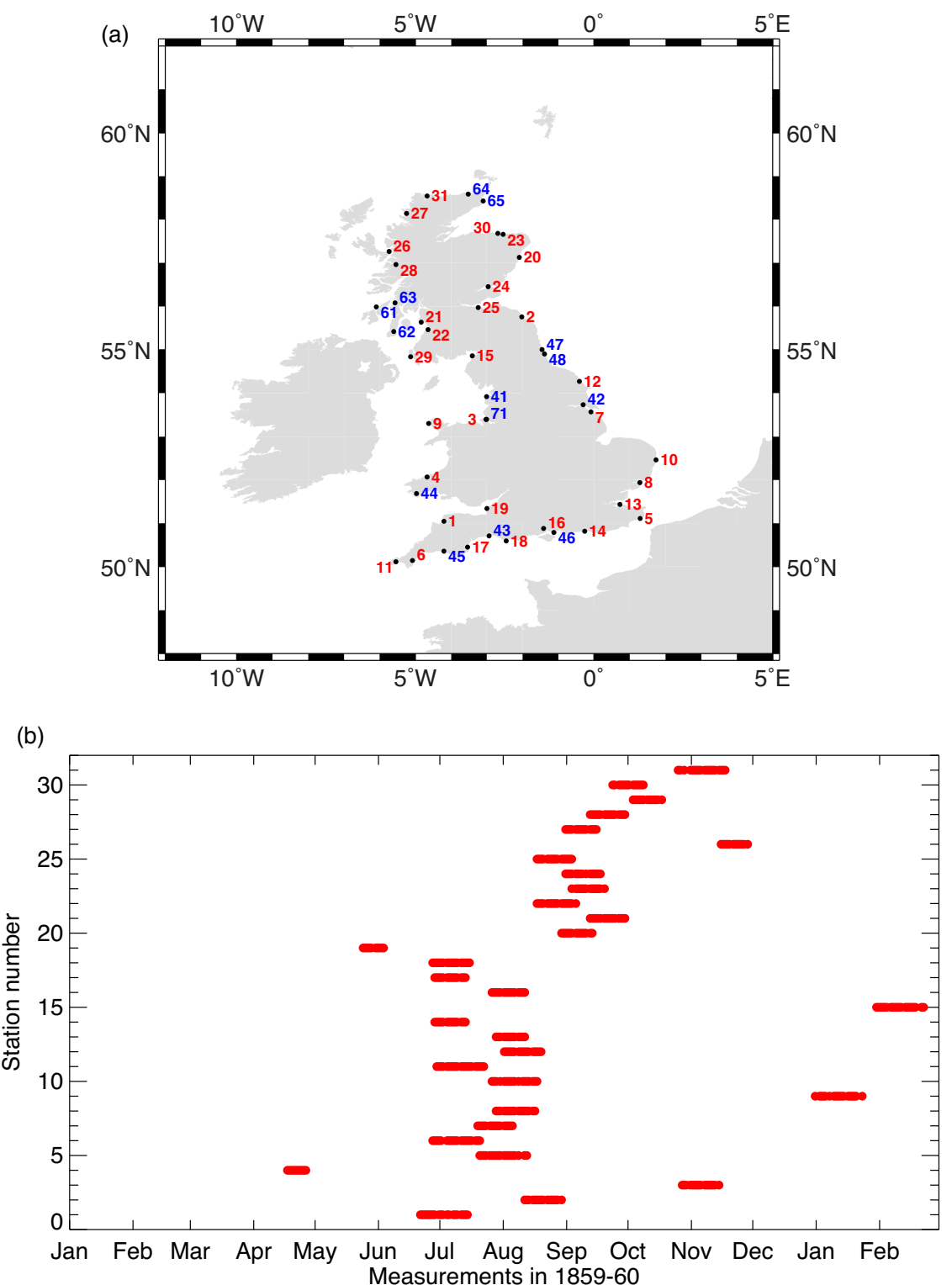

Figure 1. (a) Locations of tide gauge measurements in the First Geodetic Levelling reported in James (1861a,b). Numbers in red correspond to those in Table 1(a). Numbers in blue correspond to the additional stations in Table 1(b) and (c) discussed in Section 5.1. (b) Periods of measurements during 1859-1860 at each of the 31 historical sites in Table 1(a).

concerned. The OS had a full appreciation of the importance of documenting the datum of the measurements, in order to provide useful complementary information to the national levelling campaign.

\section{BACKGROUND TO THE MEASUREMENTS}

\subsection{Sea level measurements in 1859-1860}

Measurements at each site were made by visual observations of a tide pole every $10 \mathrm{~min}$ during daylight hours between one high (or low) tide and the next, resulting in over 70 measurements in a little over $12 \mathrm{hr}$. (Measurements were not normally made on Sundays.) In fact, James (1861a,b) states that measurements were made from about $20 \mathrm{~min}$ before the first high (or low) tide until $20 \mathrm{~min}$ after the second high (or low) tide; this uncertainty as to the actual span of the measurements is potentially an important one, as will be discussed below. The 10 min levels themselves were not recorded, but simply the average of the 70-odd sea levels between the two high (or low) tides. These separate averages were then aggregated into an overall average, covering typically a fortnight (in fact between 10 and $21 \mathrm{~d}$ depending on the site; we refer to this measurement period as a 'fortnight' below). In addition, the times and heights of the three turning points observed each day (i.e. the first and second high (or low) tides and the intervening low (or high) tide) were recorded. These heights at the turning points provide a check on the fortnightly-average sea levels at each site.

Levelling between the zeros of the tide poles and benchmarks used in the national levelling allowed the sea levels to be expressed relative to Ordnance Datum Liverpool (ODL), ODL datum having been conveyed around the country by the conventional spirit levelling during the FGL between 1840 and 1860. 


\subsection{Recent measurements of sea level}

Recent measurements of sea level at or near to the historical locations were obtained from the Permanent Service for Mean Sea Level (PSMSL, http://www.psmsl.org, Holgate et al. 2013) and British Oceanographic Data Centre (BODC, http://www.bodc.ac.uk). Both web sites have maps showing the locations of each recent station. The PSMSL information is in the form of monthly and annual values of Mean Sea Level (MSL), while that from BODC consists of hourly or $15 \mathrm{~min}$ values. The 'recent' period was defined rather generously as 1955-2014, in order to obtain data from as many sites as possible with records spanning several decades, thereby averaging over interannual and decadal variability in MSL. PSMSL data are expressed relative to Revised Local Reference (RLR) datum at each site, while BODC data are expressed relative to Admiralty Chart Datum (ACD).

The RLR and ACD datums are defined relative to the same benchmarks, which in turn have elevations that are known relative to Ordnance Datum Newlyn (ODN), the national datum that replaced ODL (Section 2.3). The relationships between RLR, ACD, ODN and benchmark heights at each station are shown in the 'RLR diagrams' on the PSMSL web site. Therefore, all recent sea levels can be expressed straightforwardly relative to ODN. A consistency check is that MSL with respect to ODN has the same spatial variation around the coastline (in particular a dependence on latitude) as noted by previous authors (Thompson 1980; Penna et al. 2013 and Supporting Information Appendix S1).

Table 1(a) shows how the historical measurements have been paired with recent ones, resulting in 38 station pairs, seven historical stations having been paired with alternative recent ones, if more than one seemed suitable. Similarly, there are seven recent stations paired with more than one historical station. In 12 cases, the pairs are at the same or a nearby location (e.g. $\sim 2 \mathrm{~km}$ apart in the cases of Penzance/Newlyn or Granton Pier/Leith or Leith II). However, other pairs are much further apart (e.g. $60 \mathrm{~km}$ for Banff/Aberdeen).

The comparison of historical to recent sea levels then depends on being able to do two things:

(1) to relate ODL to ODN levels at the historical sites, and

(2) to relate levels at the historical and recent sites, now both expressed relative to ODN, with an assumption that ODN represents a sufficiently accurate 'level' surface (i.e. a surface parallel to the geoid) between them.

In the case of pairs more distant from each other, one also has to consider the Mean Dynamic Topography (MDT, i.e. sea level relative to the geoid) between them. These aspects are discussed further below.

\subsection{ODL and ODN}

A recent summary of the history of the levellings of Great Britain has been given by Penna et al. (2013). The main aspects of interest to the present paper are as follows:

(i) The conventional spirit levelling and ODL datum of the FGL had been adequate to control the OS mapping undertaken during the late 19th century. However, deficiencies that had become apparent by the early 20 th century (see chapter 1 of Jolly \& Wolff 1922) made it clear that a Second Geodetic Levelling (SGL) was necessary, conducted to the then modern, conventional precise levelling standards and with more accurate sea level information.
The SGL was undertaken by the OS between 1912 and 1921, although the network was not extended to southeast England until as late as 1946-1951 and to Scotland until 1936-1952 (Kelsey 1972). This new campaign made use of a set of secure Fundamental Bench Marks (FBMs) installed in solid rock (rather than on buildings, etc., as before) approximately 30 miles apart at strategic points in the levelling network (Kelsey 1972, fig. 2). Heights were ultimately expressed relative to ODN datum, which was based on MSL measured at Newlyn during May 1915-April 1921 (Jolly \& Wolff 1922; Bradshaw et al. 2016).

Where the FGL and SGL levelling overlapped then it was possible to provide differences between heights expressed relative to the two datums (i.e. ODL and ODN-2 where the latter denotes ODN from the SGL). Supporting Information Fig. S2 in Supporting Information Appendix S2 reproduces Plate III from Jolly \& Wolff (1922), as published, showing the large differences that had been noted between heights measured relative to the two datums, especially in East Anglia. However, Supporting Information Fig. S3 reproduces another version of this map, which can be found inserted into the Jolly \& Wolff (1922) volume, or at least into the copy of that volume to be found at Liverpool University Library. This insert is stated to be from the Ordnance Survey (bottom right) and has a reprint number (bottom left), and appears to be an update to Plate III (Supporting Information Fig. S2). There are clear differences between the two. For example, southeast England is now contoured. However, the OS has no information on why or when the replacement map was made (Colin Fane, private communication, 2017). We return to discussion of this map in (iii). (Yet another version from the Ordnance Survey dated 1929, found in the Admiralty archives by my colleague David Pugh, is almost the same as Supporting Information Fig. S2, but again without the additional contouring in Supporting Information Fig. S3.)

(ii) A Third Geodetic Levelling (TGL) took place throughout Great Britain during 1951-1959 following many of the same traverses as the SGL (Kelsey 1972, fig. 4) and using similar instrumentation and techniques. The analysis of heights from this campaign (i.e. relative to what can be called ODN-3), when compared to those from the SGL (ODN-2), suggested physically unreasonable rates of uplift in Scotland and Wales and submergence in most of England (Kelsey 1972, fig. 5). However, the OS had already decided that TGL heights would be published 'in sympathy' with those of the SGL, resulting in a least-squares adjustment of all TGL heights while holding the FBM heights to their values from the SGL (Kelsey 1959; Christie 1994; Denker 2013).

As a consequence, there should be only minor differences at large scales between heights expressed relative to ODN-2 and ODN-3, although differences could indeed occur locally, especially at locations some distance from the FBMs and common levelling lines. The recent sea levels described in Section 2.2 above are all relative to ODN-3 (denoted now simply as ODN).

(iii) This takes us to software which the OS provides as part of its 'legacy control information', which provides interested users with differences between heights measured to the ODL and ODN datums (https://www.ordnancesurvey.co.uk/gps/legacy-controlinformation/liverpool-to-newlyn). The user enters a location in National Grid $1 \mathrm{~km}$ coordinates (e.g. a six digit number such as SW8032 for Falmouth), and the web site provides a number in feet to be added to a height in ODL in order to obtain a height in ODN. Height differences are provided in units of tenths of a foot $(3 \mathrm{~cm})$, and the accompanying text warns that values may be only approximate. If one samples this software tool for every $1 \mathrm{~km}$ 


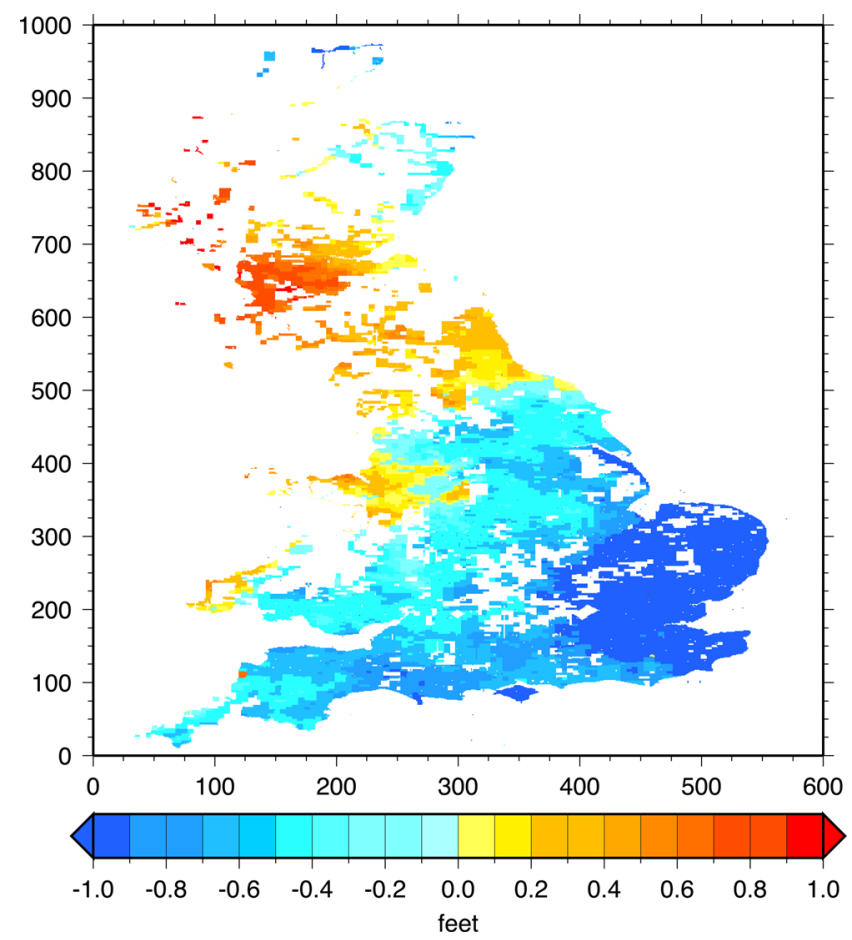

Figure 2. Differences in height measured with respect to ODN and ODL as suggested by the Ordnance Survey software tool. The abscissa and ordinate show distances in $\mathrm{km}$.

square, then one obtains Fig. 2. The blank areas in this map are coordinates for which differences are not provided by the web site, such as parts of the highlands of Scotland between levelling lines, or northern or western parts of Wales, which were not provided with FBMs in the SGL (Kelsey 1972, fig. 2). Some of the levelling lines themselves can be spotted in Fig. 2, although curiously there are gaps within some of them. There are blank areas also in Northumberland and the Scottish Borders with an isolated small patch of blue around Berwick with a value of $-0.2 \mathrm{ft}$.

Fig. 2 looks in general to be more similar to Supporting Information Fig. S3, rather than Supporting Information Fig. S2. Therefore, we consider Supporting Information Fig. S2 no further. However, a next question is whether Fig. 2 represents ODN-2 minus ODL, or rather ODN-3 minus ODL. Internal OS documentation suggests the former (Colin Fane, private communication, 2017), although the text of the web site would lead any user to assume the latter. It is hard to arrive at an answer from further inspection of Fig. 2 and Supporting Information Fig. S3, given the $0.1 \mathrm{ft}(3 \mathrm{~cm})$ precision of values provided by the web site, and the similarity between SGL and TGL heights due to the large-scale least-squares constraints explained in (ii). Values of ODN-2 minus ODL heights at $21 \mathrm{FBMs}$ near to the sites in James (1861a,b), given in a table on page 10 of Jolly \& Wolff (1922), are in reasonable agreement with values from the software tool (Fig. 3). Their difference has a mean and standard deviation of 0.02 and $0.18 \mathrm{ft}$ respectively $(0.6$ and $5.5 \mathrm{~cm})$ using all $21 \mathrm{FBMs}$, reducing to 0.01 and $0.11 \mathrm{ft}$ respectively $(0.3$ and $3.4 \mathrm{~cm})$ when the two FBMs in East Anglia said to be at 'Ipswich and Castor' are excluded. (The locations of all the FBMs were identified from their entries in http://www.bench-marks.org.uk. Ipswich and Castor are over $100 \mathrm{~km}$ apart, so it is not surprising that the locations of the two FBMs have ODN-ODL height differences using the software tool that differ by $0.9 \mathrm{ft}$. It is not clear why there was only one

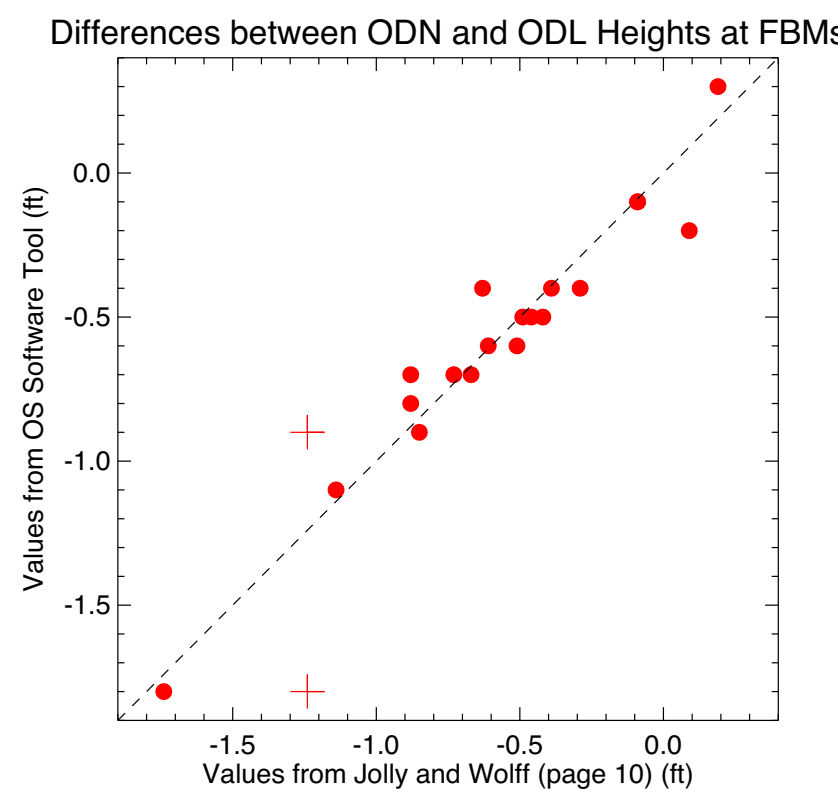

Figure 3. Differences in heights measured with respect to ODN (ODN-2) and ODL at Fundamental Bench Marks, as stated in a table on page 10 of Jolly \& Wolff (1922) and as provided by the OS software tool. The two points shown by crosses are OS values for the East Anglian FBMs at Ipswich and Castor. They correspond to only one entry in Jolly \& Wolff (1922) for an 'Ipswich and Castor' mark near to the Lowestoft tide gauge (see the text).

combined entry included for 'Ipswich and Castor' on page 10 of Jolly \& Wolff (1922)).

The analysis below makes use of this software tool, and the assumption has been made that it represents ODN (ODN-3) minus ODL, and that any differences between ODN-2 and ODN-3 are smaller than the other uncertainties in the analysis. Supporting Information Appendix S3 provides an assessment of how well the tool works at a sample of points around the coast. It gives a set of comparisons of ODN-ODL, as given by the tool, to locally understood differences in the datums as documented in the records of PSMSL and BODC. It can be seen that in all cases (apart from a questionable value at Avonmouth) there is agreement between them at the anticipated $0.1 \mathrm{ft}$ level. Supporting Information Appendix S3 also gives examples of ODN-2 and ODN-3 difference at North Shields and Milford Haven, again at the $0.1 \mathrm{ft}$ level.

The software tool enables heights expressed relative to ODL at the historical stations to be expressed relative to ODN at the same or nearby recent location. As Supporting Information Appendix S3 shows, sometimes the local relationship between ODL and ODN is documented. However, at other locations it is not, which is where the tool is important. There is no requirement thereafter to make use of the spatial dependence of ODN-ODL height differences (Fig. 2). Historical and recent heights are now both relative to ODN. Therefore, the only issue is how reliably ODN provides a 'level' surface over the relatively short distance between the historical and recent locations.

Previous authors have warned of the dangers of using ODN for scientific purposes (Christie 1994; Penna et al. 2013). However, that warning applies particularly to large scales, and here we make the reasonable assumption that ODN is sufficiently accurate over shorter distances. Nevertheless, more emphasis is placed below on the use of historical and recent pairs of stations from the same or nearby locations. 


\section{ANALYSIS METHOD}

A first check was to decide if the uncertainty over whether the tide pole observers had made $10 \mathrm{~min}$ measurements between high (or low) waters, or had made measurements also in the 20 min either side, could have affected the recorded average sea levels. In fact, on most days the number of 10 min measurements was closer to the 75 one would expect for an average $12 \mathrm{hr} 25 \mathrm{~min}$ between tides in a semidiurnal regime, rather than 79 for an additional 20 min either side. This suggests that the tide pole observers did not measure much beyond the limits of the two turning points.

An assessment of the potential importance of the uncertainty was made by generating $1 \mathrm{~min}$ tidal predictions for each location. These were derived using sets of tidal constants obtained from the National Oceanography Centre (NOC), with typically 80 constituents in each set, and the software of Bell et al. (1996). The NOC constants were computed from tide gauge measurements in recent decades. Therefore, the possibility has to be noted of long-term changes in the tides between 1859 and now, such as those due to sea level rise (e.g. Idier et al. 2017). However, such changes in the tide will have been small and will not have changed its general description.

The $1 \mathrm{~min}$ values were used to calculate the average predicted levels between the two high (or low) turning points, or with the additional $20 \mathrm{~min}$ either side. An overall average of the average predicted levels was then made over the fortnight. The difference between overall average levels, with and without the extra $2 \times 20 \mathrm{~min}$, was found to be only a few $\mathrm{cm}$ at most stations but exceeded $5 \mathrm{~cm}$ at several sites, which is a large enough value to require further investigation.

When there was a measurement over one tidal cycle from low to high to low tide (LHL), then the additional 20 min either side will obviously have been near to low tide. Therefore, any measurements from these $2 \times 20 \mathrm{~min}$ will introduce a negative bias into the average tidal level obtained from the predictions, which in turn will provide a positive bias in the tidal correction applied to the measured average sea level in (b) below. Similarly, regarding an HLH measurement, an additional $2 \times 20$ min will introduce a negative bias in the tidal correction. Because tide pole observations were made only in daylight, the measurements of sea level will have been obtained from several days of (say) LHL averages, followed by several days of HLH averages, etc., during which the tide will have changed from neaps to springs or vice versa. The overall bias in the tidal correction, therefore, depends on the number of LHL and HLH measurements, and when they occurred during the springneap cycle. Consequently, the magnitude, or even the sign, of any bias introduced by the additional $2 \times 20$ min cannot be estimated without the use of tidal predictions.

A way to resolve the question of whether the observers made measurements 20 min either side, or not, is to make use of the recorded heights of the three turning points on each day in the fortnight (i.e. the two turning points at the start and end of the tidal cycle of measurements and the one in the middle). Ideally, the average of [measured heights of the high and low waters during the fortnight minus their predicted heights] should be equal to [measured average sea level for the fortnight minus the predicted average tidal level]. A drawback of this approach comes from there being only a limited number of recorded heights at the turning points (i.e. 3 times the number of days of measurements), and these heights could contain short-lived fluctuations in level.

Nevertheless, comparison between the two quantities in brackets shows closer agreement with the observers having measured between the two high (or low) turning points, and not also within the additional 20 min either side, for 20 out of 30 of the historical stations. In fact, there are 31 historical stations in Table 1(a). The one that cannot be included in this comparison is Silloth, for which several of the recorded low waters were given to a suspiciously round number of feet, which one suspects reflects the poorer accuracy at that site of observing the low turning points during spring tides and in winter. Silloth is located in Moricambe Bay, at the head of the Solway Firth, that one suspects may come close to drying out at low water springs.

With this complicating '20 min question' answered, one can turn to using the historical sea level measurements to determine any changes in level since 1859-1860. Several corrections to these short historical measurements need to be considered. These include: (a) corrections to the observed sea levels for the seasonal cycle in MSL at each site; (b) corrections which account for the contributions of the ocean tide to the average sea levels measured over the fortnight; and (c) corrections which attempt to explain the anomalous sea levels that may have occurred in the fortnight due to unusually high or low air pressures. Each of these three corrections will vary between sites, owing to the fact that the measurement 'fortnights' took place at different times throughout 1859-1860, and because the tides vary spatially around the coastline.

(a) The seasonal cycle in MSL is the easiest to calculate. This was obtained from the PSMSL data set, using all available years of data from 1955-2014 that have information from all 12 months of the year, producing a description of the cycle in terms of 12 numbers with zero mean. Similarly, an average seasonal cycle in air pressure was calculated over 1955-2014 using 6-hourly values from the V2c version of the Twentieth Century Reanalysis Project (20CR, Compo et al. 2011, http://www.esrl.noaa.gov/psd). The analysis subsequently contains an assumption that the average seasonal cycles were the same in the 19th century as in the 20th-21st centuries.

(b) The ocean tide correction is an estimate of the bias in the average recorded sea levels due to the tide, relative to MSL. This correction can be an important, given that measurements were made over short periods between two high (or low) turning points. The correction was calculated using the 1 min tidal predictions mentioned above, which were generated without seasonal terms and which had zero MSL (or Z0) by construction, and by averaging the predicted heights between the times of the turning points during the fortnight of measurements (and not also between the 20 min either side of two high (or low) tides, as explained above).

(c) The sensitivity of sea levels measured over about a fortnight to changes in air pressure was investigated using BODC and 20CR data for the period 1955-2014. In this section of the work, more stations in BODC were used than mentioned in Section 2.2, in order to obtain a representative map of sensitivity for the UK coastline. Each year of data was divided into 2415 -d sections, ignoring the last 5 or $6 \mathrm{~d}$ of the year, and requiring that at least 80 per cent of each section had good data and also that the year as a whole was 80 per cent complete. Average sea level and air pressure were calculated for each $15 \mathrm{~d}$ section relative to the mean for that year. In addition, the monthly average values of each quantity determined from (a) were subtracted from the $15 \mathrm{~d}$ averages. The result is a data set of $15 \mathrm{~d}$ sea level and air pressure anomalies which can be compared by linear regression.

In many parts of the world, a linear regression such as this would be unnecessary as one could assume a near-inverse barometer (IB) response of sea level to air pressure change. Example areas include the east coast of the Falkland Islands (Woodworth et al. 2010), and 


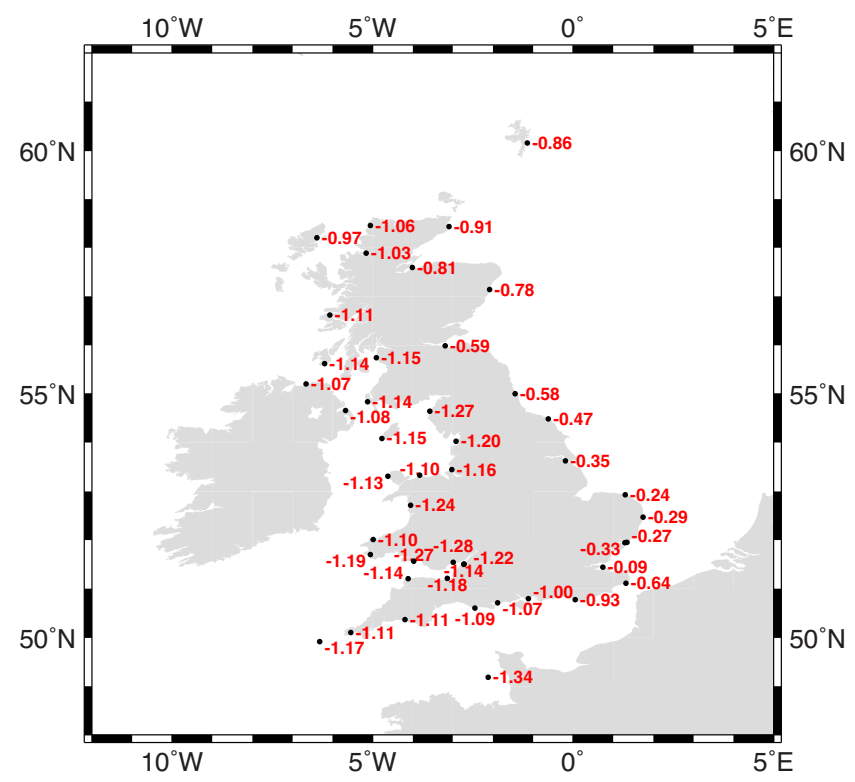

Figure 4. Regression coefficients $\left(\mathrm{cm} \mathrm{mbar}^{-1}\right)$ describing the response of sea level to changes in air pressure, using $15 \mathrm{~d}$ average values in the period 1955-2014. Sea level and air pressure data were used from BODC and the 20CR project respectively.

indeed the west coast of Great Britain to a great extent (see below). However, sea levels along the North Sea coastline are known to depart significantly from an IB-response on timescales of about a month. Fig. 4 shows the regression coefficients between sea level and air pressure (the latter being the independent variable) for the $15 \mathrm{~d}$ anomalies computed above. On the west coasts of England, Wales and Scotland, values slightly larger than $-1 \mathrm{~cm} \mathrm{mbar}{ }^{-1}$ are obtained, consistent with values obtained using monthly means (Thompson 1980; Woodworth 1987). However, North Sea coasts have much smaller values, decreasing to $-0.3 \mathrm{~cm} \mathrm{mbar}^{-1}$ around East Anglia and close to zero at Sheerness, as shown by Thompson (1980).

An air pressure correction was defined by $b \Delta p$, where $b$ is the regression coefficient and $\Delta p$ is air pressure during the fortnight relative to the mean air pressure in that year and with its seasonal cycle subtracted. One note of caution is that, although the $20 \mathrm{CR}$ data set contains values back to 1851 , its web site warns that the first decade is experimental at present. Nevertheless, given that we are using air pressure values at locations on the coast, from where some real meteorological data will have been assimilated, and not over the open ocean, we feel that the $20 \mathrm{CR}$ data set should have value in this period.

The historical sea level for the fortnight was then adjusted by applying the seasonal, tidal and air pressure corrections from (a), (b) and (c). The main uncertainty in this approach of accounting for these components of variability can be estimated from the standard deviation of the residuals in the regression (c) for the month in the year corresponding to the fortnight of the measurements. As a consequence, the standard deviation is much larger for stations when the fortnight occurred during the winter. It will be seen below that this winter uncertainty dominates the error budget for some stations.

The left-hand side of Table 1(a) gives the station number of the historical measurement, station name, and the central time of the fortnight of measurements. These are followed by the values of average sea level for each station for the historical period measured in feet relative to ODL (as given in James 1861a,b and Jolly \& Wolff 1922), the conversion from ODL to ODN datum as provided by the OS web site (in feet for ready comparison to the web site), and the resulting sea level measured relative to ODN. There follows the seasonal, tidal and air pressure corrections from (a), (b) and (c) above, followed by the best estimate of annual MSL at that time in the 19th century, again relative to ODN. For seven of the historical stations there is more than one entry owing to pairing with more than one recent station, as explained above.

The right-hand side of Table 1(a) gives the name of the nearest station with recent data in the PSMSL data set, its code number in the data set, the number of years of data in the period 1955-2014, and the overall average MSL for 1955-2014 relative to ODN. The average MSL will not need to be adjusted in any way for seasonal cycle, tides or air pressures, and the many years of data used mean that the contribution of any interannual and decadal variability to the average will have been much reduced.

Table 2(a) shows the resulting trends in sea level between the historical and recent periods and their estimated errors. The trends are determined by the differences between values of historical and recent sea levels relative to ODN from Table 1(a). Their standard errors were estimated by considering the following uncertainties:

(i) an estimate of $0.15 \mathrm{ft}(4.5 \mathrm{~cm})$ to allow for uncertainties between ODL and ODN datums, the height differences between datums provided by the OS web site being in units of $0.1 \mathrm{ft}$, as explained in Section 2.3 (iii). This value is denoted as $\sigma_{\mathrm{d}}$,

(ii) the standard deviation of residuals for the month in question from the air pressure regression in (c), denoted as $\sigma_{\mathrm{p}}$,

(iii) an estimate of the interannual variability of sea level at this location, determining how well MSL for the year in which the fortnight of historical sea level measurements occurred was representative of a longer-term MSL during the 19th century. This is denoted as $\sigma_{\mathrm{i}}$.

$\sigma_{\mathrm{i}}$ is calculated from the standard deviation of IB-corrected annual MSL values during 1955-2014, with a linear trend over this period subtracted from the values. $\sigma_{\mathrm{i}}$ has a magnitude comparable to that of $\sigma_{\mathrm{d}}$ or $\sigma_{\mathrm{p}}$ (roughly $3 \mathrm{~cm}$ ).

The question of whether interannual variability had a different magnitude in earlier years can be addressed by using the few long, continuous records from the region. Fig. 5 shows average MSL from five stations (Amsterdam/Den Helder, Brest, Sheerness, Cuxhaven and Liverpool), with each individual record detrended over the period 1901-2000 to remove vertical land movements (assumed to have rates that are constant in time). In the earlier part of the combined time series, only three stations (Amsterdam, Brest and Liverpool) contribute to the average, with all five contributing from the middle of the 19th century. The higher average values in the first half of the combined record are an artefact of the detrending during the 20th century and a small acceleration in MSL between the 19th and 20th centuries (Woodworth et al. 2011). The main point to note here is that there is no major difference in interannual variability through the centuries.

Interannual variability can also be quantified by considering annual mean air pressures which, in the 20CR data set at least, were smaller by a couple of mbar during 1859 and 1860 than in years either side (Fig. 6). Therefore, interannual variability of $\sim 2 \mathrm{~cm}$ in sea level can be inferred from the regression coefficients of order $1 \mathrm{~cm} / \mathrm{mbar}$ in Fig. 4. In fact, the lower values of air pressure in these $2 \mathrm{yr}$ are not as apparent in UK station air pressure records (e.g. see fig. 7 of Woodworth 2006, which shows annual mean air pressures from London, Liverpool and 
Table 2. (a) The 31 Ordnance Survey stations with measurements over a fortnight in 1859-1860. (b) Corresponding information for the additional stations discussed in Section 5.1. (c) Corresponding information from the $4 \mathrm{yr}$ of Liverpool MTL data (1854-1857) discussed in Section 5.1.

\begin{tabular}{|c|c|c|c|c|c|c|c|c|c|}
\hline (1) & $(2)$ & (3) & (4) & (5) & (6) & (7) & (8) & (9) & (10) \\
\hline \multicolumn{10}{|l|}{ (a) } \\
\hline 2 & Berwick & North Shields & 45.0 & 26.4 & 25.2 & 57.9 & 125.929 & 1.934 & 0.460 \\
\hline 3 & Birkenhead & L'pool Gladstone & 45.0 & 69.3 & 45.8 & 94.4 & 139.554 & 0.728 & 0.677 \\
\hline $4^{*}$ & Cardigan & Fishguard II & 45.0 & 44.4 & 32.5 & 71.1 & 140.566 & -1.274 & 0.506 \\
\hline $4^{*}$ & Cardigan & Milford Haven (Hakin) & 45.0 & 52.4 & 24.7 & 73.3 & 140.500 & -1.466 & 0.522 \\
\hline 7 & Grimsby & Immingham & 45.0 & 32.6 & 34.8 & 65.6 & 125.688 & 0.701 & 0.522 \\
\hline 8 & Harwich & Felixstowe & 45.0 & 38.7 & 35.1 & 68.9 & 135.425 & 1.225 & 0.509 \\
\hline 9 & Holyhead & Holyhead & 45.0 & 68.5 & 21.0 & 84.6 & 125.526 & 0.139 & 0.674 \\
\hline 10 & Lowestoft & Lowestoft & 45.0 & 39.1 & 27.0 & 65.4 & 126.838 & 1.544 & 0.516 \\
\hline 11 & Penzance & Newlyn & 45.0 & 25.9 & 21.2 & 56.1 & 124.131 & 1.183 & 0.452 \\
\hline 12 & Scarborough & Whitby & 45.0 & 32.1 & 35.5 & 65.7 & 137.583 & 1.727 & 0.477 \\
\hline 17 & Torquay & Plymouth & 45.0 & 28.2 & 46.1 & 70.3 & 126.109 & 0.822 & 0.557 \\
\hline 18 & Weymouth & Weymouth & 45.0 & 19.6 & 30.8 & 57.9 & 141.774 & 1.184 & 0.409 \\
\hline 19 & Weston-SM & Hinkley Point & 45.0 & 60.1 & 17.6 & 77.1 & 141.436 & 3.392 & 0.545 \\
\hline 20 & Aberdeen & Aberdeen & 45.0 & 34.5 & 27.5 & 63.0 & 124.271 & 0.588 & 0.507 \\
\hline 21 & Ardrossan & Millport & 45.0 & 41.6 & 21.1 & 64.8 & 132.950 & 1.218 & 0.487 \\
\hline 22 & Ayr & Millport & 45.0 & 43.3 & 21.1 & 65.9 & 132.991 & -0.249 & 0.496 \\
\hline 22 & Ayr & Portpatrick & 45.0 & 38.7 & 27.5 & 65.4 & 129.016 & -0.410 & 0.507 \\
\hline 23 & Banff & Aberdeen & 45.0 & 37.2 & 27.5 & 64.6 & 124.230 & 1.422 & 0.520 \\
\hline 24 & Dundee & Leith II & 45.0 & 31.1 & 27.1 & 61.1 & 142.434 & 0.017 & 0.429 \\
\hline 24 & Dundee & Leith & 45.0 & 31.1 & 26.4 & 60.7 & 103.599 & -0.023 & 0.586 \\
\hline 25 & Granton Pier & Leith II & 45.0 & 31.1 & 27.1 & 61.1 & 142.434 & 0.224 & 0.429 \\
\hline 25 & Granton Pier & Leith & 45.0 & 31.1 & 26.4 & 60.7 & 103.599 & 0.261 & 0.586 \\
\hline $26^{*}$ & Kyleakin & Tobermory & 45.0 & 62.7 & 20.1 & 79.8 & 142.241 & -1.227 & 0.561 \\
\hline \multicolumn{10}{|l|}{ (b) } \\
\hline 41 & Fleetwood & Heysham & 45.0 & 59.7 & 34.7 & 82.4 & 142.208 & 1.795 & 0.579 \\
\hline 42 & Hull & Immingham & 45.0 & 59.7 & 35.1 & 82.6 & 133.646 & 0.929 & 0.618 \\
\hline 43 & Lyme Cobb & Weymouth & 45.0 & 59.7 & 34.0 & 82.1 & 151.357 & -0.124 & 0.543 \\
\hline 44 & Pembroke & Milford Haven (Hakin) & 45.0 & 59.7 & 24.5 & 78.7 & 162.792 & 0.009 & 0.483 \\
\hline 45 & Plymouth & Plymouth & 45.0 & 59.7 & 48.4 & 89.1 & 148.609 & 1.700 & 0.599 \\
\hline 46 & Portsmouth & Portsmouth & 45.0 & 59.7 & 31.9 & 81.3 & 150.163 & 1.106 & 0.541 \\
\hline 47 & N Shields & North Shields & 45.0 & 59.7 & 24.0 & 78.5 & 130.054 & -0.220 & 0.604 \\
\hline 48 & Sunderland & North Shields & 45.0 & 59.7 & 24.0 & 78.5 & 138.054 & 0.402 & 0.569 \\
\hline 61 & Ardrissaig & Port Ellen & 45.0 & 59.7 & 30.5 & 80.7 & 150.100 & 1.489 & 0.538 \\
\hline 62 & Campbelton & Millport & 45.0 & 59.7 & 26.6 & 79.4 & 134.908 & -0.667 & 0.588 \\
\hline 63 & Crinan & Port Ellen & 45.0 & 59.7 & 30.5 & 80.7 & 150.958 & -3.552 & 0.535 \\
\hline 64 & Thurso & Wick & 45.0 & 59.7 & 29.5 & 80.4 & 145.649 & 1.681 & 0.552 \\
\hline 65 & Wick & Wick & 45.0 & 59.7 & 29.5 & 80.4 & 139.149 & 3.728 & 0.578 \\
\hline \multicolumn{10}{|l|}{ (c) } \\
\hline 71 & Liverpool & L'pool Gladstone & 45.0 & 59.7 & 45.6 & 87.6 & 143.387 & 1.753 & 0.611 \\
\hline
\end{tabular}

Columns show: $(1,2)$ Historical station number and name, (3) name of PSMSL station with recent data, followed by (4-7) the estimated uncertainties from levelling, air pressure correction and interannual variability as described in the text $\left(\sigma_{\mathrm{d}}, \sigma_{\mathrm{p}}\right.$ and $\sigma_{\mathrm{i}}$ respectively), added in quadrature to give the total error $\sigma_{\mathrm{t}}$, (units $\mathrm{mm}$ ), (8) time span between historical and recent measurements (years), resulting in $(9,10)$ the estimated sea level trend and its standard error (mm $\mathrm{yr}^{-1}$ ). Entries with an asterisk after the station number in column 1 refer to rejected station pairs as discussed in the text. 


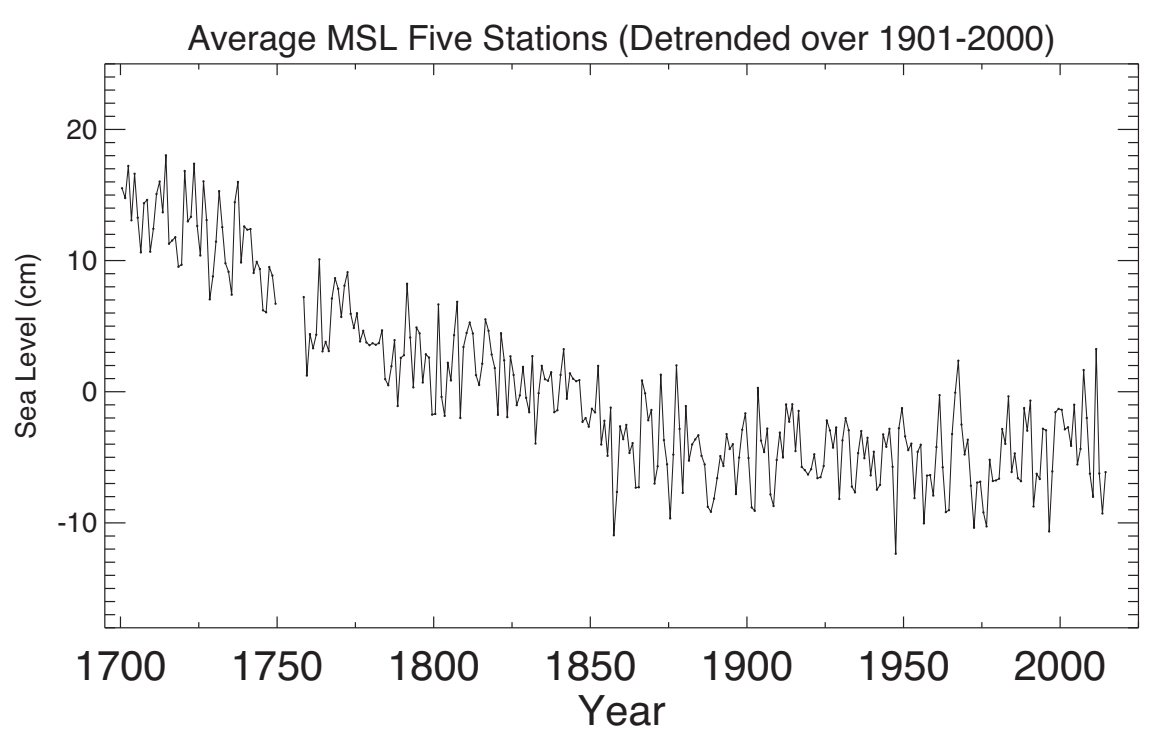

Figure 5. Average MSL from a combination of five stations (Amsterdam/Den Helder, Brest, Sheerness, Cuxhaven and Liverpool) with each station record detrended over the period 1901-2000.

Edinburgh, which confirm general features of the time series in Fig. 6 such as the low air pressure in 1872 and lower values between 1910 and 1940). This suggests that regional air pressures for the $1850 \mathrm{~s}$ in the $20 \mathrm{CR}$ data set may be capable of further improvement.

Mention should also be made of long period tides, which might have contributed unequally to the historical and recent measured sea levels. These tides have periods of about a fortnight, month and the nodal period of $18.61 \mathrm{yr}$ (Woodworth 2012). The latter is the only one worth considering with regard to the recent sea levels. However, the many years of annual MSL information used means that any nodal contribution to the recent averages will be negligible. As regards the historical data, the fact that measurements were made over approximately a fortnight means that any contribution from the fortnightly long period tides will have been averaged out. Any contributions from the monthly tides (which have centimetric amplitudes around the UK) will be included in the residuals of the air pressure regression in (c), and so contribute to $\sigma_{\mathrm{p}}$. Interannual variability due to the nodal tide in the historical period will be the same as that at present times and any uncertainty due to that will be included automatically in $\sigma_{\mathrm{i}}$. In principle, in addition to considering uncertainties, one could make an explicit nodal adjustment to the 1859-1860 sea levels. However, if the nodal tide has its expected equilibrium form (Woodworth 2012), then any such adjustment would be less than $0.5 \mathrm{~cm}$ at UK latitudes, and so can also be considered negligible. That conclusion is confirmed by no nodal signal being evident in Fig. 5 .

The total error $\sigma_{\mathrm{t}}$ of the historical sea level is also shown in Table 2(a). This quantity was computed by adding $\sigma_{\mathrm{d}}, \sigma_{\mathrm{p}}$ and $\sigma_{\mathrm{i}}$ in quadrature and, when divided by the span of time between historical and recent measurements, provides the standard error on the trend.

One might also consider other uncertainties. For example, for historical/recent pairs of stations some distance apart, then one should allow for the spatial variation in MDT between them (e.g. fig. 6 of Hipkin et al. 2004). Many pairs in Table 1(a,b) were either at the same location, or the distances between them were small. Therefore, any differences in MDT should be centimetric and can be considered negligible. However, one area where this will not be the case is the Bristol Channel where MDT increases by $\sim 30 \mathrm{~cm}$ as one travels upstream towards the River Severn (see fig. 12 of Iliffe et al. 2007). This rapidly changing MDT is an important consideration for the Weston-super-Mare/Hinkley Point pair, which are $20 \mathrm{~km}$ apart (see next section and Supporting Information Appendix S1). It is less of an issue for Appledore/Ilfracombe, that are $15 \mathrm{~km}$ apart and also on the south bank of the Bristol Channel, but are closer to the Celtic Sea where the spatial gradient in MDT is smaller.

Other errors may be more systematic than statistical. For example, Dover is seen in the next section to be an outlier. Its anomalous long-term trend requires the datum of the historical (or recent) sea levels to have been wrong by a large amount (about $30 \mathrm{~cm}$ or $1 \mathrm{ft}$ ). Supporting Information Appendix S1 shows that MSL above ODN for the present data conforms with MSL values for its neighbours, whereas MSL for the historical data had an anomalously low value. Therefore, it is tempting to blame this outlier as an error in the datum reported for the historical Dover data (e.g. the reported relationship between tide gauge zero and ODL). However, this conclusion is contradicted by the fact that sea level measured at Dover in 1896, by the same organization and using the same methods and reference level (ODL), was said to be almost identical to that in 1859 (Section 5.2). In addition, Roberts (1913) reported MSL for Dover during 1883-1884 to have a similar value above ODL, although differing by almost a foot $(30 \mathrm{~cm})$ from that in 1910 . This Dover puzzle remains unexplained, but meanwhile one must assume that the historical data must be in error by about a foot. To compound the problem, the Dover recent MSL record spanning 1961-2015 has a couple of gaps, with suspicions of datum shifts between them, although its overall MSL trend in this period is similar to that of other south of England stations.

\section{SEA LEVEL TRENDS}

Fig. 7 plots the trends in Table 2(a) as a function of latitude. Several pairs of stations have been omitted from the plot for reasons explained above. These include the pair with the historical station at Cardigan in west Wales, which is up a river and on the fringes of the levelling networks. Similarly, the pairs with historical stations in NW Scotland (Kyleakin, Lochinver, Oban and Rispond) have been omitted, as they are also on the fringes of the levelling 

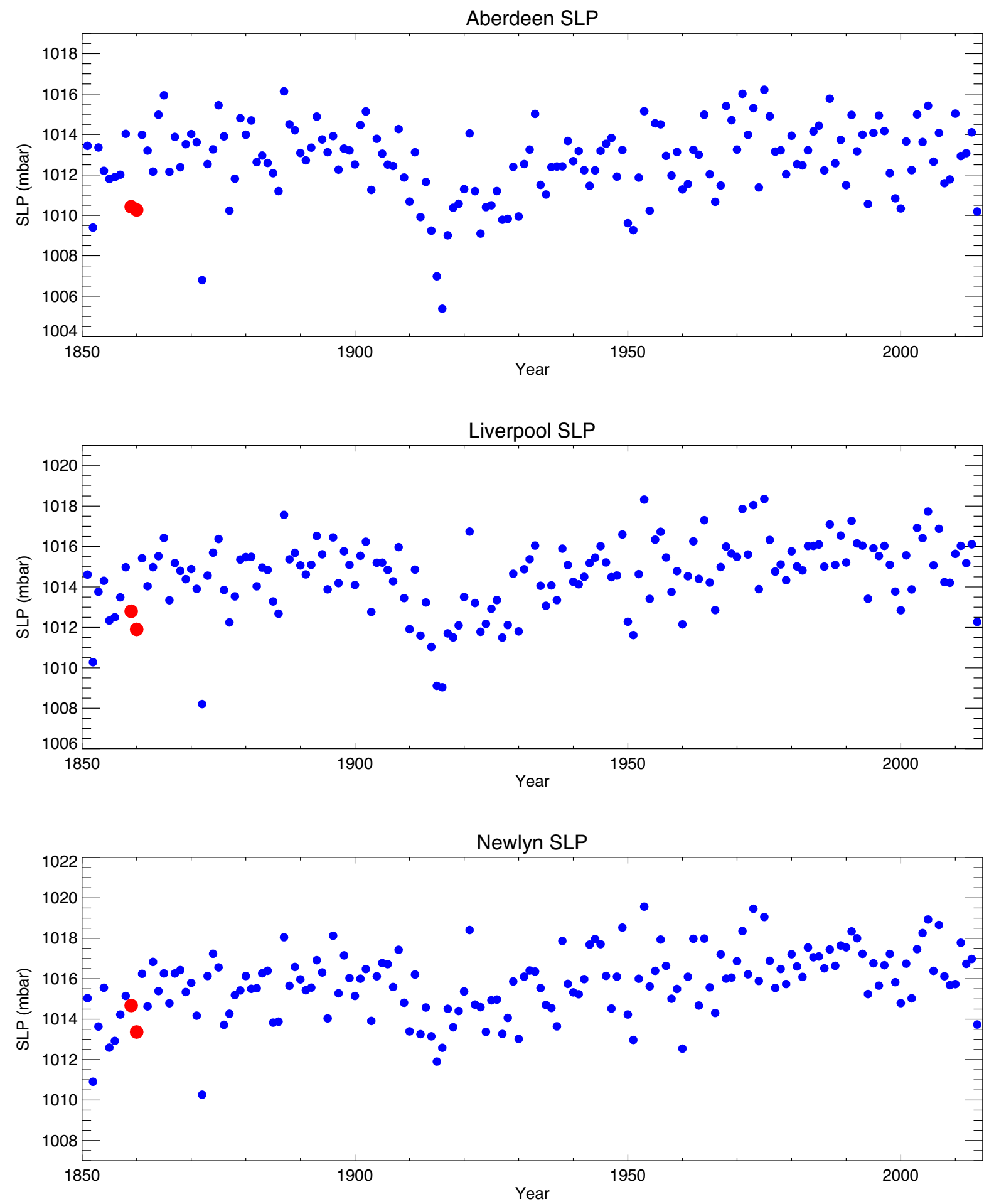

Figure 6. Annual mean sea level air pressure (SLP) at Newlyn, Liverpool and Aberdeen in the 20CR/V2c data set. 1859 and 1860 values are shown in red.

networks, and some distance from their recent partners. (The historical Rispond sea levels may also be unrepresentative owing to the measurements having been made during an exceptionally stormy period in October-November 1859, see Supporting Information Appendix S5).

At several of these rejected sites, the OS software tool gives very different values for ODN-ODL at the historical and recent stations, by half a foot or more. This does not necessarily mean that ODN is not a good approximation of a level surface (and ODL was a good surface), or vice versa. Rather, it simply casts doubt on the accuracy of both sets of local levelling near to those stations, which is another reason for their rejection.

In addition, in the case of some pairs on the west coast of Scotland (those with Millport, Tobermory and Port Ellen as the recent stations), there is a requirement for there having been an accurate transfer of ODN over $\sim 2 \mathrm{~km}$ of water, which may be problematical for the accuracies needed here. The Oban pairings with Tobermory and Port Ellen were anyway rejected for the ODN-ODL differences 


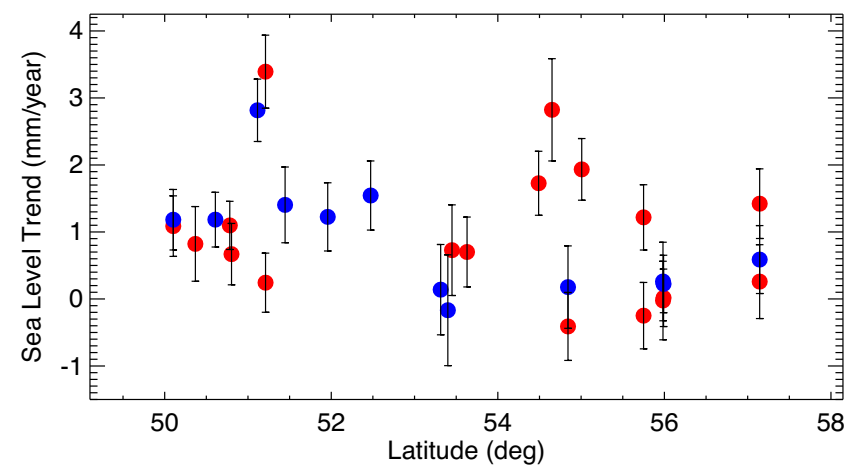

Figure 7. Trends in sea level $\left(\mathrm{mm} \mathrm{yr}^{-1}\right)$ plotted versus latitude. Blue dots indicate station pairs at the same, or nearby, location, while red dots indicate pairs some distance apart.

mentioned above, so are not an issue. The Ardrossan and Ayr pairings with Millport have been left in the data set for now.

The trends for the stations in Fig. 7 are almost all positive, with the pairs containing historical and recent stations at the same, or nearby, locations (shown in blue) suggestive of a tighter grouping. In the case of Aberdeen (just above $57^{\circ} \mathrm{N}$ ), the recent record has been paired in Table 1(a) with three historical ones (Aberdeen, Banff and Portsoy), and it is gratifying that the trend using Aberdeen itself falls between those for the two other historical stations that are some $60 \mathrm{~km}$ distant. Similarly, there is good agreement between pairs at Granton Pier/Leith and Leith II, which are only $\sim 2 \mathrm{~km}$ apart, and also Dundee with the two recent Leith stations, about $50 \mathrm{~km}$ apart (shown at $56^{\circ} \mathrm{N}$ ). Other pairings in Scotland of a recent record and two historical stations include recent Portpatrick, paired with historical stations at Portpatrick itself and Ayr (shown at $54.8^{\circ} \mathrm{N}$ ), and recent Millport with historical Ardrossan and Ayr (shown at $\left.55.8^{\circ} \mathrm{N}\right)$.

A decrease of trend with latitude can be inferred within the scatter of points. Otherwise, there are three positive outliers that can be mentioned. The blue dot at $51^{\circ} \mathrm{N}$ is for Dover. Why this should be an outlier is not understood (see above). The BODC archives suggest that there had been confusion in the past about datum differences of $0.2 \mathrm{ft}(6.1 \mathrm{~cm})$ (Supporting Information Appendix S3); however, this is not enough to explain the anomalous value. The red dot at slightly higher latitude is for Weston-super-Mare/Hinkley Point. This pair was mentioned in the previous section, and if one allows for a difference of $\sim 20 \mathrm{~cm}$ in MDT between them, the $3.4 \mathrm{~mm} \mathrm{yr}^{-1}$ for the red dot in Fig. 7 reduces to about $2.0 \mathrm{~mm} \mathrm{yr}^{-1}$. The other positive outlier shown by the red dot above $54.5^{\circ} \mathrm{N}$ corresponds to the Silloth/Workington pair, which are $30 \mathrm{~km}$ apart, and for which the Silloth data may have been affected by the coarse measurements near to low tides mentioned above.

These trends can be compared to those anticipated for the present day, based on geological measurements of sea level during the Late Holocene together with modelling of Glacial Isostatic Adjustment (Bradley et al. 2011; Shennan et al. 2012). Fig. 8 shows values of trends in Table 2(a) compared to those of relative sea level in fig. 9(a) of Bradley et al. (2011) (and fig. 6 of Shennan et al. 2012). It shows that there is some correlation between them within the large scatter, providing a confirmation of the spatial dependence of vertical land movements in the UK as represented by the Bradley et al. (2011) model. The correlation also provides an explanation for the apparent decrease of trend with latitude in Fig. 7. (The line in Fig. 8 is intended to guide the eye only: it has a slope of 0.68 instead of the ideal 1.0.)

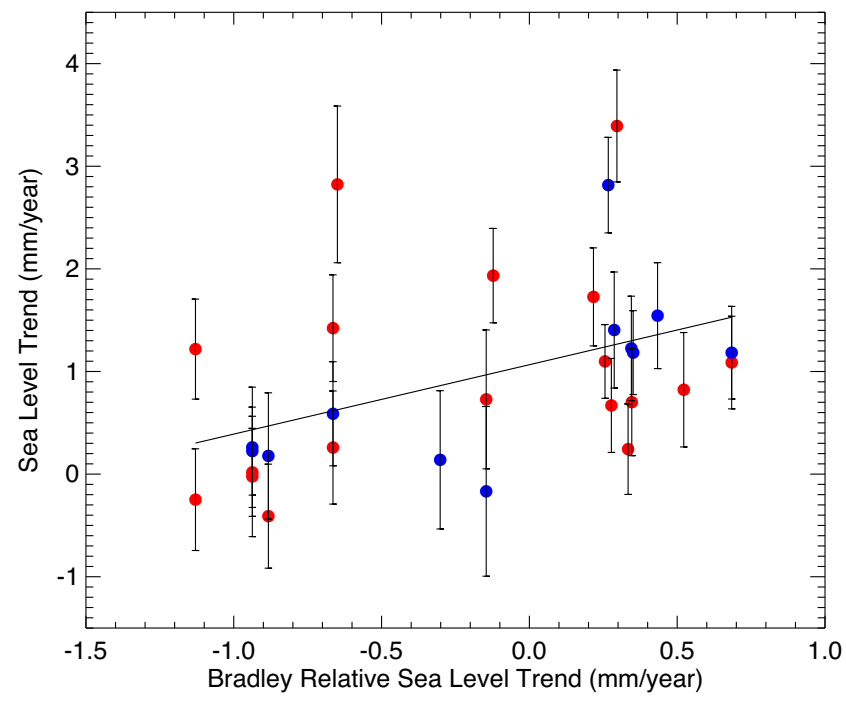

Figure 8. Trends in sea level from Fig. 7 compared to those from the model of Bradley et al. (2011).
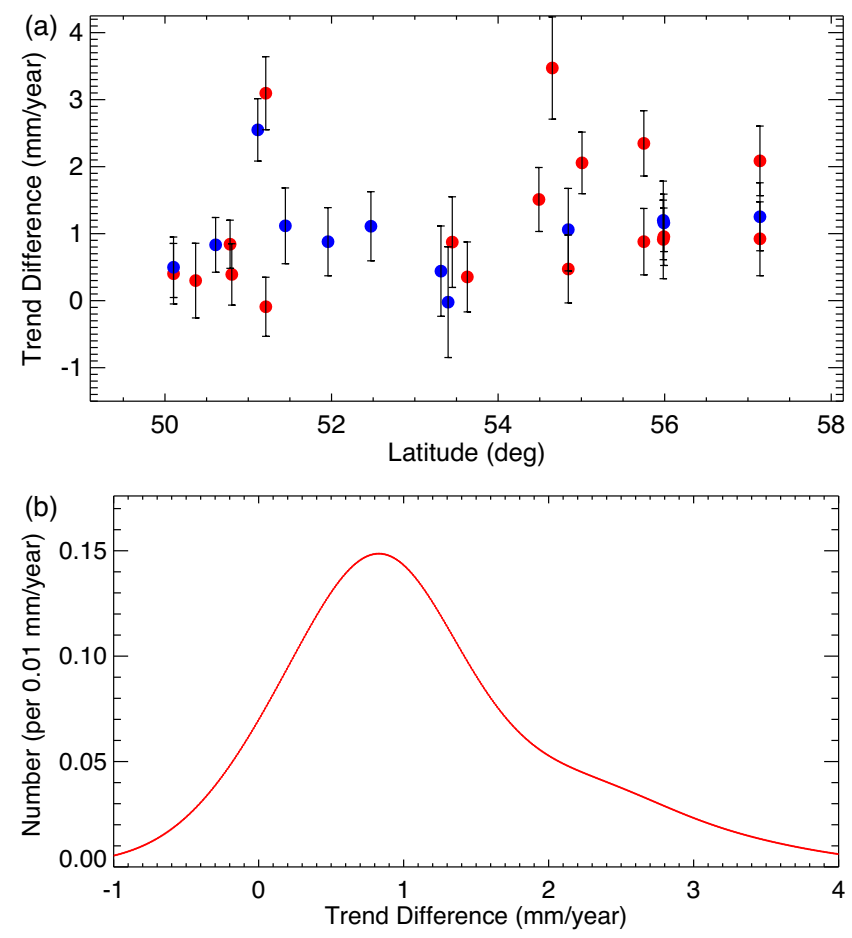

Figure 9. (a) Differences between the trends shown in Fig. 7 and those from the model of Bradley et al. (2011). (b) A probability distribution of trend difference obtained by combining the values shown in (a).

The use of such 'baseline trends' provides a way to determine the extent to which trends observed during the 19th-21st centuries may be a consequence of recent climate change. Fig. 9(a) plots measured minus Bradley trends as a function of latitude. The difference can be seen to be similar at all latitudes (apart from the three outliers discussed above), suggesting a uniform rate of climate-related sea level rise around the coast. Fig. 9(b) makes the assumption that the trend differences are independent of latitude, and combines them into one probability distribution. A contribution from each trend difference value was spread over a normal distribution with a central value given by the trend difference and a standard deviation given by its standard error. The area under the red curve sums 
Table 3. Long-term trends in sea level $\left(\mathrm{mm} \mathrm{yr}^{-1}\right)$ obtained in the present paper (Table 2a for Aberdeen and Sheerness, Table 2c for Liverpool), and number of years of data, data span and overall trend $\left(\mathrm{mm} \mathrm{yr}^{-1}\right)$ for the three sites in the UK with near-continuous MSL records since the mid-19th century. The latter use MSL data updated from that in Woodworth et al. (2009).

\begin{tabular}{lclrr}
\hline Historic/Recent Stations & Trend from Tables 2a and 2c & \multicolumn{1}{c}{ Station } & No. Years & Data span \\
\hline Aberdeen/Aberdeen & $0.59 \pm 0.51$ & Aberdeen (composite) & 141 & $1862-2014$ \\
Sheerness/Sheerness & $1.40 \pm 0.57$ & Sheerness & 78 & $1834-2006$ \\
Liverpool/L'pool Gladstone & $1.75 \pm 0.61$ & Liverpool (composite) & 101 & $1.617 \pm 0.057$ \\
\hline
\end{tabular}

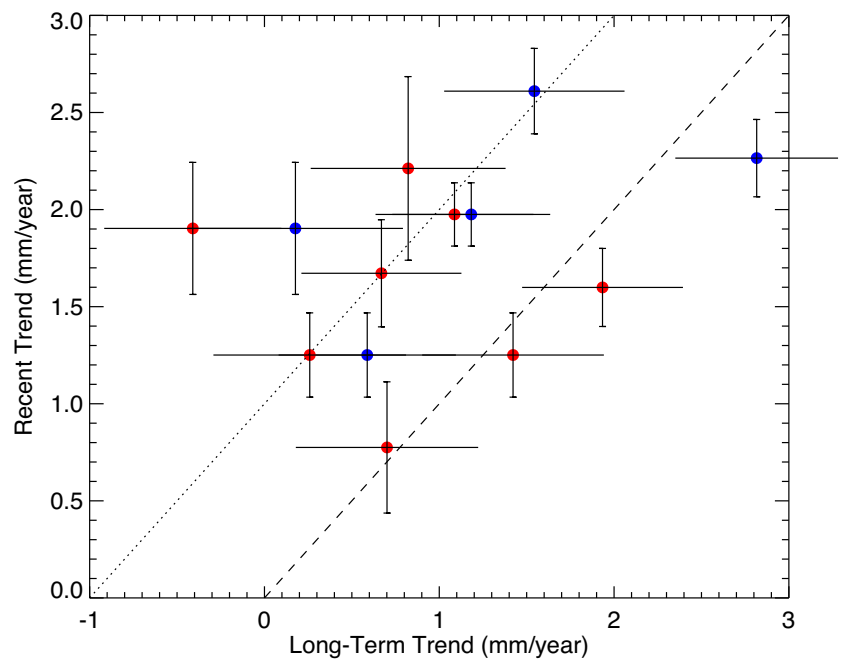

Figure 10. Trends in MSL during 1955-2014 compared to the long-term trends from Table 2(a). Station pairs with points near to the dotted line have recent trends $1 \mathrm{~mm} \mathrm{yr}^{-1}$ larger than their long-term trends.

to the 30 values in Fig. 9(a). As could already be inferred from inspection of Fig. 9(a), the best overall estimate of trend difference (the mode of the distribution) is $0.83 \mathrm{~mm} \mathrm{yr}^{-1}$ with a standard error of $0.69 \mathrm{~mm} \mathrm{yr}^{-1}$, calculated from the full-width half-maximum divided by 2.355 . (The median of the slightly skewed distribution is $1.00 \mathrm{~mm} \mathrm{yr}^{-1}$.)

Two of the trends based on the use of short historical records can be compared to those obtained from long, near-continuous MSL records. Aberdeen and Sheerness (and Liverpool to be discussed in the following section) are the only sites in the UK with nearcontinuous MSL information since the mid-19th century. Table 3 shows that trends at the two locations obtained by the alternative techniques are in good agreement. In principle, one could also compare the trends obtained from the Birkenhead/Birkenhead and Birkenhead/Liverpool Gladstone pairs in Table 2(a) to that from the long record from Liverpool, Birkenhead being located only $\sim 1$ mile away on the west bank of the Mersey opposite Liverpool. These two options give smaller trends (Table 2a) than that of the long record (Table 3), which can be explained either by a datum uncertainty in the historical Birkenhead record or, more likely, by an unrepresentative set of sea level measurements during Birkenhead's observation fortnight in 1859 (Supporting Information Appendix S5).

To see whether trends in sea level may have changed significantly in recent decades compared to the long-term rates, Fig. 10 compares trends in IB-corrected MSL for recent stations with at least $40 \mathrm{yr}$ of data during 1955-2014 to the long-term rates from Table 2(a). There are 13 entries in the figure derived from 9 independent recent stations (Aberdeen, North Shields, Immingham, Lowestoft, Portsmouth Plymouth, Dover, Newlyn and Portpatrick), there being two entries for the recent stations at Newlyn and Portpatrick and three for Aberdeen (as shown by the pairings in Table 1a).

The documentation for each station on the PSMSL web site, and previous studies of UK sea level (e.g. Woodworth et al. 1999, 2009) have expressed reservations as to the quality of several MSL records for determination of secular trends; in the above set, Plymouth (Devonport) is probably the most unreliable. Nevertheless, at face value at least, it can be seen that most recent trend values exceed the long-term trends by about $1 \mathrm{~mm} \mathrm{yr}^{-1}$, as shown by the dotted line, with the major exception again of Dover shown by the blue dot to the right of the plot. (The three red dots closer to the dashed line are for Portsmouth, Aberdeen and Immingham). An excess of $1 \mathrm{~mm} \mathrm{yr}^{-1}$ in the recent epoch is consistent with an acceleration from the mid-19th to the 21 st centuries with a quadratic coefficient of $\sim 1 \mathrm{~mm} \mathrm{yr}^{-1}$ per century.

\section{ADDITIONAL HISTORICAL I NFOR MATION}

\subsection{Additional MTL information in James (1861a,b)}

James (1861a,b) mentions additional estimates of MTL, from eight stations in England Wales and five stations in Scotland, derived mostly from measurements in earlier years by the Admiralty. The locations of these stations are shown in Fig. 1(a) in blue, and their average sea levels are summarized in Table 1(b). Details of the measurements are given in Supporting Information Appendix S4. These stations are a bit of a mixed bag. On one hand, all of them are based on measurements spanning a longer period than those of Table 1(a), and so one might consider them to be of greater value. In fact, three of them (from the Admiralty Dockyards at Pembroke, Plymouth and Portsmouth) span four complete years; these historical records from the 19th century are discussed in detail in a report by David Pugh (2017).

On the other hand, several of them appear to be of lesser value. For example, estimates of average sea level from all the Scottish stations (except for Wick) were obtained from measurements over disjointed periods of time. In addition, they are from sites on the fringes of the levelling networks where the ODL to ODN relationship will be more uncertain, and are some distance from their recent partners, often separated by mountainous terrain.

All of these additional records are stated, or assumed, to be of MTL rather than MSL. Therefore, any MTL value has to be adjusted to give a best estimate of MSL, prior to its comparison to recent MSL values from the PSMSL. This adjustment can be large (over a decimetre), and different in sign, at different points around the coast. However, in most cases, the adjustment can be calculated to good accuracy if one has good tidal constants at, or near to, the location in question. The main tidal constants are those of the M4 and M6 constituents (Pugh \& Woodworth 2014). However, diurnal constituents also play a role, and in practice the adjustment needs to be calculated using as full a set of tidal constants as possible. 
Methods for making that calculation are described by Woodworth (2017).

Otherwise, the procedure for estimating changes in MSL between the historical and recent periods, and in particular the importance of knowing the relationship between ODL and ODN datums at each site, is similar to that described above for the 31 OS stations; Tables 1(b) and 2(b) provide the corresponding information for these 13 additional stations.

The seasonal corrections in Table 1(b) were calculated as for those in Table 1(a); those shown as zero correspond to records with complete years of data. The method for computing differences between MTL and MSL has been outlined above. The main difference to Table 1(a) is that air pressure corrections are not possible as these data are from before 1851 when the $20 \mathrm{CR} / \mathrm{V} 2 \mathrm{c}$ data set starts. Therefore, it is set to zero in Table 1(b). Its uncertainty $\left(\sigma_{\mathrm{p}}\right)$ in Table 2(b) is estimated as $5.97 \mathrm{~cm}$ for all stations. This is the standard deviation in mbar of monthly mean air pressure at Aberdeen. This will be a conservative estimate of the real $\sigma_{\mathrm{p}}$ at each historical station, given that all of the historical records in Table 1(b) span several months or years, rather than a single month, and given that Aberdeen is further north than most records in the additional set.

Table 2(b) is given here for completeness, but trend values from these additional stations have not been included in Fig. 7 and later figures. Many of the estimated trends can be disregarded. For example, the Scottish ones (with the possible exceptions of Thurso/Wick and Wick/Wick) can be excluded for the same concerns about distant ODN connections given above. North Shields/North Shields and North Shields/Sunderland give small trends, which would be expected if their historical measurements had been too high, which is a conclusion from the 1896 measurements at these locations mentioned in the next section. Even though Hull/Immingham provides a trend value similar to many in Table 1(a), it has to be considered only approximate given the difference of about $0.6 \mathrm{ft}$ between ODN-ODL heights either side of the Humber (Fig. 2) and consequent concerns as to ODN being a level surface. (The same consideration applies to Grimsby/Immingham in Table 1(a)). Fleetwood/Heysham also has a trend that looks plausible, although Supporting Information Appendix S4 explains that there was uncertainty regarding the datums of two historical sets of Fleetwood data. Lyme Cobb/Weymouth is based on what seems to be limited data in winter 1849 . That leaves the three Admiralty dockyard pairs of Pembroke/Milford Haven, Plymouth/Plymouth and Portsmouth/Portsmouth. The datum relationships for Pembroke/Milford Haven will be less reliable than for the other two, which result in trends similar to those in Table 2(a).

The introduction to James (1861a) also mentions short measurements at three Thames ports and Ramsgate (Supporting Information Appendix S4). The former are too far up-river, have no recent partner, and pre-date the start of the 20CR data set. Therefore, we have not investigated them in detail. In addition, James (1861a) refers to a month of MSL data in May-June 1859 at Liverpool, which will have eventually formed part of the Liverpool (George's Pier) PSMSL record commencing in 1858. More interestingly, it gives four annual MTL values (1854-1857) which pre-date the PSMSL record. These estimates of MTL are referred to in Tables 1(c) and 2(c), and subsequently provide a trend which gives an acceptable comparison to the long, near-continuous record from Liverpool in Table 3.

\subsection{OS measurements in 1896}

In 1896, the War Office requested the Ordnance Survey to determine for military purposes the mean level of the sea at various coast fortresses. That request coincided with a revision of the large-scale maps of England and Wales that had recently been commenced by the OS. Therefore, it was decided that a new set of tidal measurements should be made in order to confirm whether the measurements made in 1859-1860 remained 'approximately good'. The same methods, and fortnightly periods of measurement, were employed as previously, at various times between January and November of that year (but few in March-April and September-October). Findings were presented in Ordnance Survey (1899) and reproduced in Jolly \& Wolff (1922).

Unfortunately, Ordnance Survey (1899) contains no information on the actual dates of the fortnights of measurements at each site, or even the seasons, and there is no surviving additional information at the OS itself (Colin Fane, private communication, 2017). Therefore, it has not been possible to consider making seasonal, tidal and air pressure to the 1896 measured values, as made for the earlier ones in $1859-1860$.

Nevertheless, one can make a face-value comparison of the average sea levels reported in the two campaigns, both sets of averages referred to ODL. Some stations from 1859-1860 were not repeated in 1896, and the 1896 set did not include stations in Scotland. In addition, there were several other stations in 1896 that were not represented in 1859-1860, which leaves 18 stations for comparison.

Average sea levels in the two campaigns were found agree to within half a foot $(15 \mathrm{~cm})$ at 12 of the 18 sites. This level of agreement is to be expected given that the 1896 data are not adjusted either for a seasonal cycle of about a decimetre, or for tidal or air pressure corrections. As mentioned above, Dover values differ by only $0.1 \mathrm{ft}$ between $1859-1860$ and 1896 , so its outlier status in Section 4 remains unexplained.

The six sites with larger differences include Cardigan and Silloth, both with problems in 1859-1860 mentioned above. They also include North Shields and Sunderland, where the Ordnance Survey made the measurements in 1896 . However, their earlier values of average sea level (Tables $1 \mathrm{~b}$ and $2 \mathrm{~b}$ ) were taken from Admiralty measurements (Supporting Information Appendix S4) and were about a foot higher than those recorded in 1896. One suspects confusion between datums in these cases. The remaining two sites are Holyhead and Penzance, each of which differs by about $0.7 \mathrm{ft}$ between 1859-1860 and 1896. It is hard to judge between the two sets of 1859-1860 and 1896 values, except to remark that the smaller trend for Holyhead in Table 2(a) would be consistent with its sea level in 1859-1860 having been overestimated by $0.7 \mathrm{ft}$. On the other hand, the trend for Penzance in Table 2(a), based on its 1859-1860 value, appear similar to expectations.

\section{CONCLUSIONS}

There are some aspects of this work that could be done more accurately one day. For example, where there are concerns as to the datum of measurements (e.g. Dover), then further research could perhaps throw more light on them. In particular, research of the extensive Ordnance Survey historical records deposited at the National Archives could help in this way. In addition, the relationships between ODL and ODN near to each tide gauge, verified to some extent as described in Supporting Information Appendix S3, could be tightened by identification of as many benchmarks as possible that were used in both the FGL and SGL. The heights of benchmarks, relative to ODL and ODN separately, can be obtained from various historical sources. (My colleague David Pugh has already made such research for a number of sites.) Another useful activity would be to identify any surviving marks that were used in the FGL 
only, and then to undertake a new levelling connection between them and any nearby marks from the SGL and TGL.

A second improvement could come from improved modelling of the response of sea levels to changes in air pressures and winds during the mid-19th century. The 20CR data set has already been used to derive catalogues of Lamb Weather Types for the British Isles (Jones et al. 2013) and to model changes in cyclone activity around the UK and Ireland back to 1871 (Matthews et al. 2016). It has also been used to model daily storm surge levels on a global basis since 1871 (Cid et al. 2017). As the 20CR continues to improve and to be extended further into the past, then one can expect it to be applied in reliable storm surge modelling for earlier periods.

Nevertheless, it has been shown that the analysis method described above results in estimated errors on historical sea levels that provide useful estimates of long-term trends. Although each set of historical measurements spans only about a fortnight, it has to be emphasized that there are many sites involved, that each one can be considered as providing an independent trend estimate, and that measurements were performed by competent staff from a major geodetic agency. In addition, measurements were undertaken at different times of the year at different places, and so involve different seasonal, tidal and meteorological corrections. The reliance on using ODN to connect some pairs of historical and recent stations when they are separated by $10 \mathrm{~s}$ of $\mathrm{km}$ is admittedly problematical. However, the approach seems to have worked reasonably well, although of course it has been correct to focus on findings from pairs of stations from the same or nearby locations.

Overall, the comparison of historical and recent data provides evidence that sea level around the UK rose during the past one and half centuries, by $\sim 1 \mathrm{~mm} \mathrm{yr}^{-1}$ more than one would expect based on modelling of long-term changes in sea and land levels due to ongoing geological processes. This conclusion is consistent with the $1.4 \mathrm{~mm} \mathrm{yr}^{-1}$ estimated for UK sea level change for 1901-onwards obtained from the permanent tide gauges in the UK network together with geological and geodetic information (Woodworth et al. 2009), the period 1901-onwards being about two-thirds that of 1859-onwards. In addition, the long-term changes seem to be similar at various points around the coast.

Furthermore, sea level trends from the most recent decades (1955-2014) exceed those for the longer period (1859-2014) by approximately $1 \mathrm{~mm} \mathrm{yr}^{-1}$, confirming the acceleration of sea level rise from the mid-19th to the $20 \mathrm{th} / 21$ st centuries that had been observed previously only in a small number of continuous tide gauge records.

A fortnight of historical sea level data sounds an extremely small data set from which to extract long-term information. However, it has been shown that, as long as the datum of the measurements is reliable, and that a long interval of time separates the historical and recent measurements, then interesting findings can be obtained. Of course, it is better to have as many small data sets as possible. 'Data archaeology' and 'data rescue' are required for the sea level archives of various UK organizations to be comprehensively catalogued, and then for the most suitable information to be converted into computer form, in order to make it available for research. One would hope that the use of more such historical records, however short, from the UK and neighbouring countries will provide greater insight into regional sea level change.

\section{ACKNOWLEDGEMENTS}

I am grateful to Colin Fane (Ordnance Survey), Nigel Penna (Newcastle University) and David Pugh (National Oceanography Centre) for advice on several aspects of this work, and to Sarah Bradley (University of Bristol, now at Delft University of Technology) for information in Bradley et al. (2011). Ordnance Survey (1899) was provided by Christopher Jones (UK Hydrographic Office). Part of this work was funded by UK Natural Environment Research Council National Capability funding. Some figures were generated using the Generic Mapping Tools (Wessel \& Smith 1998). Computer files with transcriptions of the Ordnance Survey 1859-1860 data set may be obtained from the author and have been lodged with the British Oceanographic Data Centre.

\section{REFERENCES}

Allan, R. et al., 2011. The International Atmospheric Circulation Reconstructions over the Earth (ACRE) initiative, Bull. Am. Meteorol. Soc., 92(11), 1421-1425.

Barlow, N.L.M. et al., 2014. Salt-marsh reconstructions of relative sea-level change in the North Atlantic during the last 2000 years, Quat. Sci. Rev., 99, 1-16.

Bell, C. et al., 1996. The Tidal Analysis Software Kit (TASK Package), TASK-2000 version dated December 1998, National Oceanography Centre, Liverpool.

Bradley, S.L. et al., 2011. An improved Glacial Isostatic Adjustment model for the British Isles, J. Quat. Sci., 26(5), 541-552.

Bradshaw, E. et al., 2015. Sea level data archaeology and the Global Sea Level Observing System (GLOSS), GeoResJ, 6, 9-16.

Bradshaw, E. et al., 2016. A century of sea level measurements at Newlyn, Southwest England, Mar. Geod., 39(2), 115-140.

Christie, R.R., 1994. A new geodetic heighting strategy for Great Britain, Surv. Rev., 32(252), 328-343.

Cid, A. et al., 2017. Global reconstructed daily surge levels from the 20th Century Reanalysis (1871-2010), Glob. Planet. Change, 148, 9-21.

Compo, G.P. et al., 2011. The twentieth century reanalysis project, Q. J. R. Meteorol. Soc., 137(654), 1-28.

Denker, H., 2013. Regional gravity field modeling: theory and practical results, Chapter 5, in Sciences of Geodesy - II. Innovations and Future Developments, pp. 185-291, ed. Xu, G., Springer-Verlag.

Hipkin, R.G. et al., 2004. The geoid EDIN2000 and mean sea surface topography around the British Isles, Geophys. J. Int., 157(2), 565-577.

Hogarth, P., 2014. Preliminary analysis of acceleration of sea level rise through the twentieth century using extended tide gauge data sets (August 2014), J. geophys. Res., 119(11), 7645-7659.

Holgate, S.J. et al., 2013. New data systems and products at the Permanent Service for Mean Sea Level, J. Coast. Res., 29, 493-504.

Idier, D. et al., 2017. Sea-level rise impacts on the tides of the European Shelf, Cont. Shelf Res., 137, 56-71.

Iliffe, J.C. et al., 2007. A new methodology for incorporating tide gauge data in sea surface topography models, Mar. Geod., 30(4), 271-296.

James, H., 1861a. Abstracts of the Principal Lines of Spirit Levelling in England and Wales, Ordnance Survey.

James, H., 1861b. Abstracts of the Principal Lines of Spirit Levelling in Scotland, Ordnance Survey.

Jolly, H.P.L.G. \& Wolff, A.J., 1922. The Second Geodetic Levelling of England and Wales 1912-1921, Ordnance Survey by HMSO.

Jones, P.D. et al., 2013. Lamb weather types derived from reanalysis products, Int. J. Climatol., 33(5), 1129-1139.

Hunter, J. et al., 2003. The sea level at Port Arthur, Tasmania, from 1841 to the present, Geophys. Res. Lett., 30(7), 1401, doi:10.1029/2002GL016813.

Kelsey, J., 1959. Matters arising from the completion of the third geodetic levelling of England and Wales, in Proceedings of the Conference of Commonwealth Survey Officers 1959, HMSO 1960, pp. 226-248.

Kelsey, J., 1972. Geodetic aspects concerning possible subsidence in southeastern England, Phil. Trans. R. Soc. A, 272(1221), 141-149. 
Levitus, S., 2012. The UNESCO-IOC-IODE "Global Oceanographic Data Archeology and Rescue" (GODAR) Project and "World Ocean Database" Project, Data Sci. J., 11(0), 46-71.

Long, A.J. et al., 2014. Contrasting records of sea-level change in the eastern and western North Atlantic during the last 300 years, Earth planet. Sci. Lett., 338, 110-122.

Matthews, T. et al., 2016. A cyclone climatology of the British-Irish Isles 1871-2012, Int. J. Climatol., 36(3), 1299-1312.

Ordnance Survey, 1899. Spirit levelling in England and Wales, Abstracts of tidal observations, Ordnance Survey Internal Document.

Penna, N.T. et al., 2013. The apparent British sea slope is caused by systematic errors in the levelling-based vertical datum, Geophys. J. Int., 194(2), 772-786.

Pugh, D.T. \& Woodworth, P.L., 2014. Sea-Level Science: Understanding Tides, Surges, Tsunamis and Mean Sea-Level Changes, pp. 408, Cambridge University Press.

Roberts, E., 1913. Re-reduction of Dover tidal observations, 1883-84, etc., Proc. R. Soc. A, 88(602), 230-233.

Shennan, I. et al., 2012. Late Holocene vertical land motion and relative sea-level changes: lessons from the British Isles, J. Quat. Sci., 27(1), 64-70.

Testut, L. et al., 2006. The sea level at Port-aux-Français, Kerguelen Island, from 1949 to the present, Ocean Dyn., 56(5-6), 464-472.

Testut, L. et al., 2010. Sea level at Saint Paul Island, southern Indian Ocean, from 1874 to the present, J. geophys. Res., 115(C12), C12028, doi:10.1029/2010JC006404.

Thompson, K.R., 1980. An analysis of British monthly mean sea level, Geophys. J. Int., 63(1), 57-73.

Watson, C. et al., 2010. Twentieth century constraints on sea level change and earthquake deformation at Macquarie Island, Geophys. J. Int., 182(2), 781-796.

Wessel, P. \& Smith, W.H.F., 1998. New, improved version of generic mapping tools released, EOS, Trans. Am. geophys. Un., 79(47), 579-579.

Woodworth, P.L., 1987. Trends in U.K. mean sea level, Mar. Geod., 11(1), $57-87$.

Woodworth, P.L. \& Jarvis, J., 1991. A feasibility study of the use of short historical and short modern tide gauge records to investigate long term sea level changes in the British Isles, Proudman Oceanographic Laboratory Internal Document No. 23, 32pp. and figures.

Woodworth, P.L. et al., 1999. A review of the trends observed in British Isles mean sea level data measured by tide gauges, Geophys. J. Int., 136(3), $651-670$.

Woodworth, P.L., 1999. High waters at Liverpool since 1768: the UK's longest sea level record, Geophys. Res. Lett., 26(11), 15891592.

Woodworth, P.L., 2006. The meteorological data of William Hutchinson and a Liverpool air pressure time series spanning 1768-1999, Int. J. Climatol., 26(12), 1713-1726.

Woodworth, P.L. et al., 2009. Trends in UK mean sea level revisited, Geophys. J. Int., 176(1), 19-30.
Woodworth, P.L. et al., 2010. Long-term and recent changes in sea level in the Falkland Islands, J. geophys. Res., 115(C9), C09025, doi:10.1029/2010JC006113.

Woodworth, P.L. et al., 2011. Evidence for century-timescale acceleration in mean sea levels and for recent changes in extreme sea levels, Surv. Geophys., 32(4-5), 603-618 (erratum page 619), doi:10.1007/s10712011-9112-8.

Woodworth, P.L., 2012. A note on the nodal tide in sea level records, J. Coast. Res., 28, 316-323.

Woodworth, P.L., 2017. Differences between mean tide level and mean sea level, J. Geod., 91, 69-90.

\section{SUPPORTING INFORMATION}

Supplementary data are available at $G J I$ online.

Figure S1. Fig. S1 is almost the same as fig. 3(d) of Penna et al. (2013) which was made using stations with at least $37 \mathrm{yr}$ of recent data between 1974 and 2011. Hinkley Point is shown by the red diamond, with a higher MSL because of the large MDT in the upper parts of the Bristol Channel discussed in the text. Blue points show MSL above ODN for the historical data, after the various corrections have been applied, and converted from ODL to ODN datum. (Again, the overall average was subtracted from each value of MSL.) Points are plotted at the latitude of the recent station in each pair, hence, for example, three blue dots at the same latitude as Aberdeen, see Table 1(a). The blue diamond refers to Weston-super-Mare which is nearer to the Celtic Sea than Hinkley Point, which gives it a smaller MDT. The blue star refers to Dover which lies significantly below recent MSL at Dover shown by the red star.

Figure S2. Plate III from Jolly \& Wolff (1922) showing differences in height measured with respect to Newlyn datum (ODN) in the SGL and with respect to Liverpool datum (ODL) in the FGL.

Figure S3. An insert, clearly originating from the Ordnance Survey, attached to the copy of Jolly \& Wolff (1922) in Liverpool University Library. This map is presumably an update to Plate III (Fig. S2).

Figure S4. The barometer (top, in inches $\mathrm{Hg}$ ) and temperature record $\left({ }^{\circ} \mathrm{F}\right)$ from Wakefield during October-November 1859 presented by Dobson (1860).

Figure S5. Six-hourly values of sea level air pressure (SLP) at Wakefield from the 20CR data set.

Please note: Oxford University Press is not responsible for the content or functionality of any supporting materials supplied by the authors. Any queries (other than missing material) should be directed to the corresponding author for the paper. 